\title{
Polygonatum sibiricum polysaccharide inhibits IL-1 $\beta$-induced inflammation in human chondrocytes
}

\author{
Jun WU ${ }^{1 \#}$, Xinyu ZHANG ${ }^{2 *}$, Suqin $\mathrm{HU}^{3}$, Suohua PAN ${ }^{1}$, Cunliang $\mathrm{WANG}^{4 *}$ (D)
}

\begin{abstract}
Osteoarthritis (OA) is a degenerative joint disease associated with inflammation. Polygonatum sibiricum polysaccharide (PSP) is a major group of active components isolated from Polygonatum sibiricum with broad activities including anti-inflammatory effect. However, the role of PSP in OA is unclear. In the present study, we aimed to investigate the effects of PSP on IL- $1 \beta$-induced inflammatory response in primary human OA chondrocytes. The results showed that PSP improved cell viability of chondrocytes in response to IL-1 $\beta$ induction. The increased levels of several inflammatory mediators including nitric oxide (NO), prostaglandin E2 (PGE2), inducible nitric oxide synthase (iNOS) and cyclooxygenase-2 (COX-2) in IL-1 $\beta$-induced chondrocytes were attenuated by PSP in a dose-dependent manner. The IL- $1 \beta$-induced production of pro-inflammatory cytokines, TNF- $\alpha$ and IL-6, were mitigated by PSP in chondrocytes. Besides, PSP also suppressed the production of matrix metalloproteinases (MMPs), including MMP-1, MMP-3 and MMP-13 in IL-1 $\beta$-stimulated chondrocytes. Furthermore, the IL- $1 \beta$-induced activation of NF- $\mathrm{KB}$ signaling pathway in chondrocytes was also prevented by PSP. These findings suggested that PSP alleviated IL- $1 \beta$-induced inflammatory response in chondrocytes via inhibiting NF- $\mathrm{KB}$ signaling pathway.
\end{abstract}

Keywords: Osteoarthritis (OA); Polygonatum sibiricum polysaccharide (PSP); chondrocytes; inflammation; inflammatory mediators; NF- $\mathrm{kB}$ signaling pathway.

Practical Application: PSP might serve as a potential anti-osteoarthritic agent.

\section{Introduction}

Osteoarthritis (OA) is a degenerative joint disease and leading cause of morbidity and physical limitation among the elderly population (Loeser et al., 2012). Major clinical symptoms of OA include radiographic joint space narrowing, joint instability, stiffness, and chronic pain, therefore, leading to remarkable decreased living quality (Felson, 2006). Pathological examinations show that $\mathrm{OA}$ is characterized by articular cartilage degradation, subchondral bone sclerosis, osteophyte formation, and inflammation (Malemud, 2015; Shen et al., 2017). A better understanding of the pathogenesis of OA may provide evidence for developing novel therapeutic strategies.

Growing number of studies prove that inflammatory response plays crucial roles in the development of OA (Marchev et al., 2017; Shen et al., 2017). Upregulation of inflammatory mediators has been observed in synovial cells, articular chondrocytes and other cell types of diarthrodial cartilage (Rahmati et al., 2016). The inflammatory mediators lead to the degradation of cartilage extracellular matrix (ECM) via regulating the expressions of matrix metalloproteinases (MMPs) and a disintegrin and metalloproteinase with thrombospondin motifs (ADAMTSs) (Scanzello, 2017). It has been proposed that targeting the inflammation might be a promising strategy for the treatment of OA (Shen et al., 2017).

Polygonatum sibiricum (PS) is a natural plant used in traditional Chinese belonged to the genus Polygonatum (Zhao et al., 2018). The traditional use of PS has been confirmed by a large body of pharmacological studies, which are attributed to the presence of multiple components (Cui et al., 2018). Of these, polysaccharide isolated from PS (PSP) plays a major role in the PS-based therapeutics due to its broad biological activities, such as anti-oxidant, anti-bacterial, anti-inflammatory, anti-atherosclerotic, anti-osteoporosis, and anti-cancer effects (Cui et al., 2018). However, the role of PSP in OA remains unclear. Thus, the objective of this study was to evaluate the effect of PSP on inflammatory response in human OA chondrocytes exposed to interleukin-1 $\beta$ (IL-1 $\beta$ ).

* These authors contributed equally to this work.

${ }^{1}$ Orthopedics Department, Eastern Theater General Hospital, Nanjing, China

${ }^{2}$ Orthopedics Department, The Fourth Medical Center of PLA General Hospital, Beijing, China

${ }^{3}$ Outpatient Department, Eastern Theater General Hospital, Nanjing, China

${ }^{4}$ Orthopedics Department, Yangling Demonstration Zone Hospital, Xianyang, China

*Corresponding author: wangcl1965@126.com 


\section{Material and methods}

\subsection{Primary human $O A$ chondrocyte culture}

Human cartilage samples were obtained from 10 OA patients who underwent total knee replacement surgery at Eastern theater General Hospital (Nanjing, China). Tissue collection and application was approved by the Medical Ethical Committee of Eastern theater General Hospital.

Chondrocytes were isolated from cartilage samples as described previously (Chen et al., 2018). The cartilage samples were sectioned into pieces and treated with $0.25 \%$ trypsin $/ 0.02 \%$ EDTA for $1 \mathrm{~h}$, and then incubated with $0.2 \%$ type II collagenase at $37{ }^{\circ} \mathrm{C}$ overnight in an incubator. After filtration and centrifugation, cells were resuspended in DMEM/F12 medium (Gibco Laboratories, Grand Island, NY, USA), including 10\% FBS and $1 \%$ antibiotics (penicillin and streptomycin) in an incubator containing $5 \% \mathrm{CO}_{2}$. The second or third generation was used in subsequent experiments.

Chondrocytes were treated with recombinant IL-1 $\beta$ (10 ng/ml; Peprotech GmbH, Hamburg, Germany) for $24 \mathrm{~h}$. For the PSP treatment groups, cells were pretreated with 6.25, 12.5 and $25 \mu \mathrm{M}$ PSP (purity > 98\%; Chengdu institute of biology, Chinese academy of sciences, Chengdu, China), followed by IL- $1 \beta$ stimulation.

\subsection{Cell viability assay}

Cell viability of chondrocytes was measured with MTT assay. The chondrocytes were placed into 96-well microtiter plates at a density of $1 \times 10^{4}$ cells per well and subjected to different treatments. After that, $20 \mu \mathrm{L}$ of $5 \mathrm{mg} / \mathrm{ml} \mathrm{MTT}$ solution (Sigma-Aldrich, St. Louis, MO, USA) was added to each well. After incubation for $4 \mathrm{~h}$, the culture medium was replaced by $150 \mu \mathrm{l}$ of DMSO for formazan solubilization. Finally, the absorbance value at $490 \mathrm{~nm}$ was measured using a microplate reader.

\subsection{Measurement of Nitric Oxide (NO)}

The NO concentration in the culture medium was measured using a Total NO Assay Kit (R\&D Systems, Minneapolis, MN, USA) by estimating the production of nitrite based on the Griess reagent.

\section{4 $q R T-P C R$}

Total RNA was extracted from chondrocytes using the RNeasy Protect Mini kit (Qiagen, Hilden, Germany). The first strand of complementary DNA (cDNA) was synthesized from $1 \mu \mathrm{g}$ of the total RNA using the SuperScript ${ }^{\mathrm{TM}}$ First-Strand Synthesis System (Invitrogen, Waltham, MA, USA). Then PCR reaction was performed using $2 \times$ SYBR Green Master Mix (TaKaRa, Dalian, China) on the ABI PRISM 7900HT Sequence Detection System (Applied Biosystems, Foster, CA, USA). The relative mRNA levels of target genes were determined using $2^{-\Delta \Delta \mathrm{Ct}}$ method. The primers were listed: $\beta$-actin (F) 5'-CAC ACT GTG CCC ATC TAC GA-3', (R) 5'-CTC AGT GAG GAT CTT CAT GAG GTA GT-3'; inducible nitric oxide synthase (iNOS) (F) 5' -TCC
AGG AGG ACA TAC AGC AC-3', (R) 5'-CGC CCT TCC GCA GTT CT-3'; cyclooxygenase-2 (COX-2) (F) 5' -TGA GTA CCG CAA ACG CTT CTC-3', (R) 5'-TGG ACG AGG TTT TTC CAC CAG-3'; TNF- $a$ (F) 5'-ACG GCA TGG ATC TCA AAG AC-3', (R) 5'-GTG GGT GAG GAG CAC GTA GT-3'; IL-6 (F) 5'-CTG CAA GAG ACT TCC ATC CAG TT-3', (R) 5'-GAA GTA GGG AAG GCC GTG G-3’.

\subsection{Western blot}

Chondrocytes were washed with PBS for three times and lysed with RIPA lysis buffer (Beyotime Biotechnology, Shanghai, China) for $30 \mathrm{~min}$ at $4{ }^{\circ} \mathrm{C}$. Then, protein concentration in the whole cell extracts was determined using a BCA Protein Assay Kit (Beyotime). An equivalent amount of protein samples $(40 \mu \mathrm{g})$ were mixed with loading buffer and boiled for $5 \mathrm{~min}$. After that, the proteins were subjected to $12 \%$ SDS-PAGE gel electrophoresis and transferred onto nitrocellulose (NC) membranes. The membranes were blocked with a blocking solution (5\% nonfat milk in TBST buffer) for $2 \mathrm{~h}$ at room temperature and then incubated with rabbit polyclonal antibody (diluted 1: 1000; Abcam, Cambridge, MA, USA) against iNOS, COX-2, p-p65, p65, p-IkBa or $\beta$-actin overnight at $4{ }^{\circ} \mathrm{C}$. After washing for three times with TBST, the membranes were incubated with HRP conjugated goat anti-rabbit IgG (diluted 1: 3000; Abcam) for $1 \mathrm{~h}$ at room temperature. Finally, the immunoreactive bands were visualized using ECL detection kit (Thermo Fisher Scientific, Waltham, MA, USA) according to the manufacturer's instructions.

\subsection{Enzyme-linked Immunosorbent assay (ELISA)}

The contents of prostaglandin E2 (PGE2), TNF- $a$, IL-6, MMP-1, MMP-3 and MMP-13 in the culture supernatants were measured using corresponding ELISA kits (R\&D Systems, Minneapolis, MN, USA) according to the manufacture's protocol.

\subsection{Statistical analysis}

All data were presented as the means \pm SEM. Statistical analyses were performed using SPSS16.0 (SPSS Inc., Chicago, IL, USA) with one-way analysis of variance (ANOVA) followed by Tukey post hoc test. $P<0.05$ indicated statistical significance.

\section{Results}

\subsection{PSP reversed IL-1 $\beta$-induced reduction in cell viability}

First, we examined the cytotoxic effect of PSP on chondrocytes, chondrocytes were treated with various concentrations of $\operatorname{PSP}(0,6.25,12.5,25$ and $50 \mu \mathrm{M})$ for $24 \mathrm{~h}$. The results showed that the highest concentration of PSP $(50 \mu \mathrm{M})$ decreased chondrocyte viability, while PSP at concentrations of $0-25 \mu \mathrm{M}$ was not cytotoxic to chondrocytes (Figure 1A). So, we selected 0-25 $\mu \mathrm{M}$ PSP for the subsequent experiments. In addition, we observed that compared with the control group, cell viability in the IL- $1 \beta$ induction group was significantly decreased. 
A

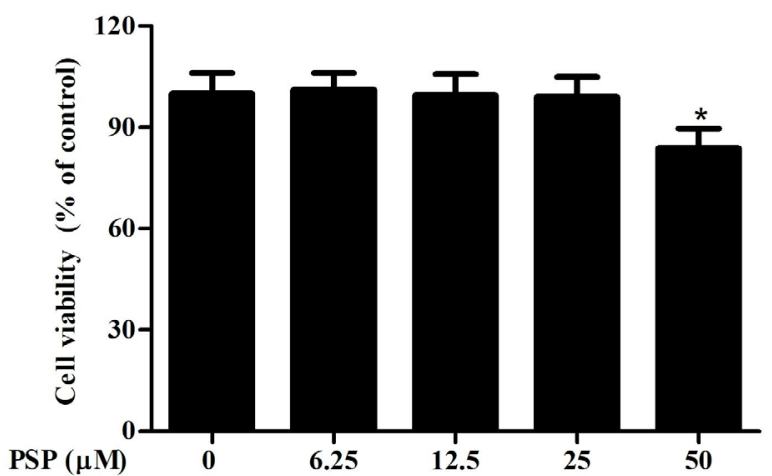

B

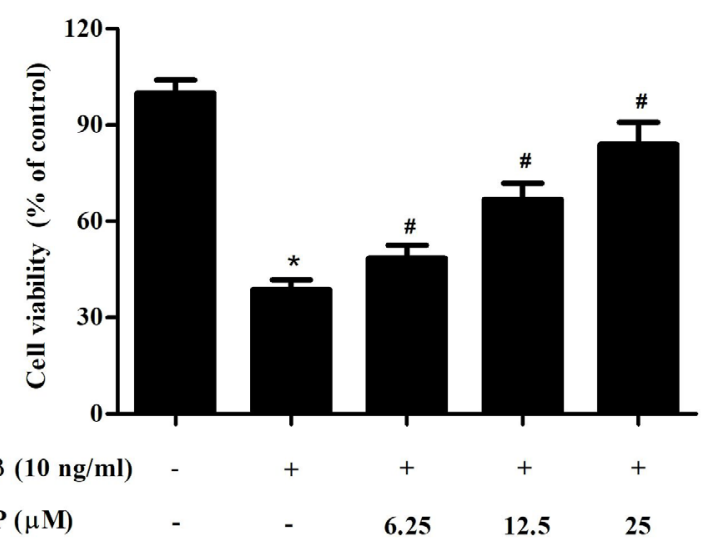

Figure 1. PSP improved cell viability of IL- $1 \beta$-induced chondrocytes. (A) Effect of PSP treatment (24h) on the cell viability of chondrocytes; (B) Chondrocytes were treated with recombinant IL-1 $\beta(10 \mathrm{ng} / \mathrm{ml})$ for $24 \mathrm{~h}$ with or without the pretreatment of $6.25,12.5$ and $25 \mu \mathrm{M}$ PSP for $2 \mathrm{~h}$; Cell viability was measured using MTT assay; ${ }^{\star}$ indicated $p<0.05$ vs. control group; \# indicated $p<0.05$ vs. IL- $1 \beta$ stimulation group.

In addition, PSP improved the cell viability in a dose-dependent manner (Figure 1B).

\subsection{PSP suppressed NO and PGE2 production in IL-1 $\beta$ - induced human $\mathrm{OA}$ chondrocytes}

Then we measured the production of inflammatory mediators, $\mathrm{NO}$ and PGE2. Compared with the control group, IL-1 $\beta$ induced a significant increase in the production of NO and PGE2 (Figures 2A, B). However, the increased $\mathrm{NO}$ and PGE2 production were suppressed by PSP in a dose-dependent manner.

\subsection{PSP suppressed iNOS and COX-2 expression in IL-1 $\beta$-induced human $O A$ chondrocytes}

Next, the expression levels of iNOS and COX-2 were measured using qRT-PCR and western blot. As shown in
A
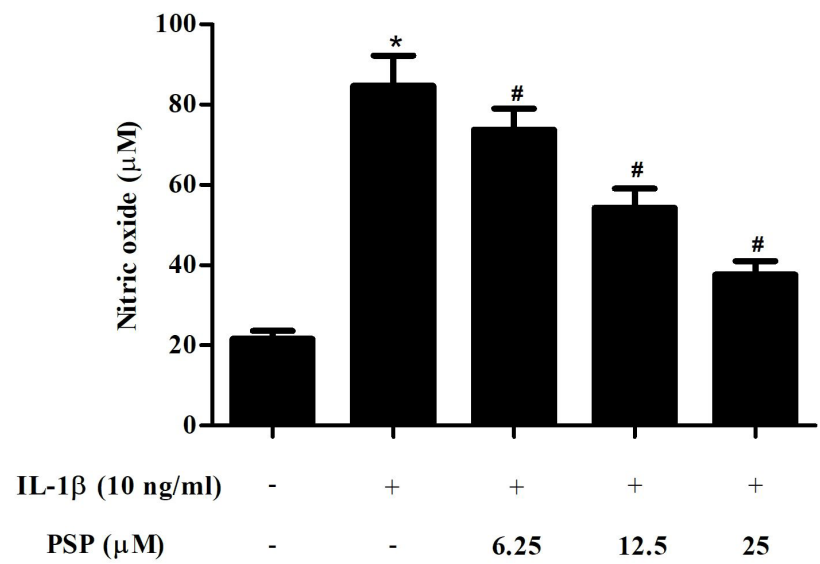

B

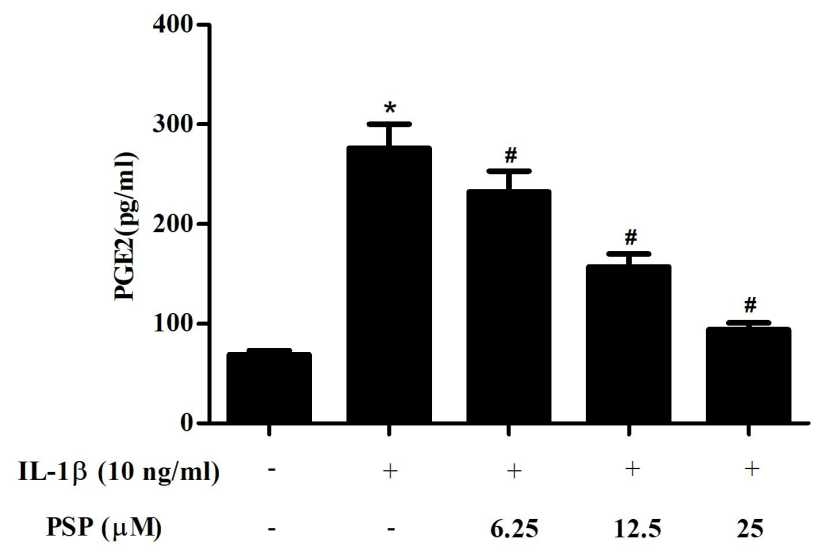

Figure 2. PSP suppressed IL-1 $\beta$-induced production of NO and PGE2 in chondrocytes. Chondrocytes were treated with recombinant IL- $1 \beta$ $(10 \mathrm{ng} / \mathrm{ml})$ for $24 \mathrm{~h}$ with or without the pretreatment of $6.25,12.5$ and $25 \mu \mathrm{M}$ PSP for $2 \mathrm{~h}$; (A) The NO levels in the culture medium were assessed by Griess reaction; (B) The PGE2 levels in the culture medium were determined by ELISA; ${ }^{\star}$ indicated $p<0.05$ vs. control group; \# indicated $p<0.05$ vs. IL- $1 \beta$ stimulation group.

Figures 3A, B, the mRNA levels of iNOS and COX-2 were elevated by IL- $1 \beta$ induction, while PSP attenuated the increase in mRNA levels of iNOS and COX-2. Besides, PSP also greatly inhibited IL- $1 \beta$-induced increase in the protein levels of iNOS and COX-2 (Figure 3C).

\subsection{PSP suppressed the production of TNF- $\alpha$ and IL-6 in IL-1 $\beta$-stimulated human OA chondrocytes}

Subsequently, the production of inflammatory cytokines including TNF- $\alpha$ and IL- 6 were measured. The results of qRT-PCR showed that IL- $1 \beta$-stimulated increase in TNF- $\alpha$ and IL- 6 mRNA levels were mitigated by PSP (Figures 4 A, B). ELISA results proved that the production of TNF- $\alpha$ and IL- 6 in supernatant were significantly decreased after treatment with PSP (Figures 4C, D). 
A

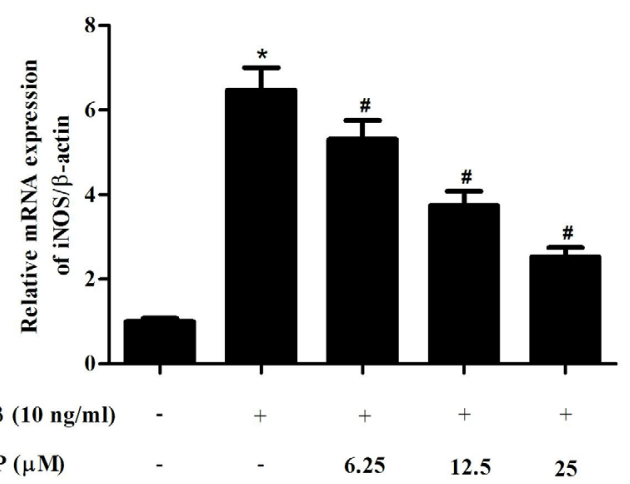

B

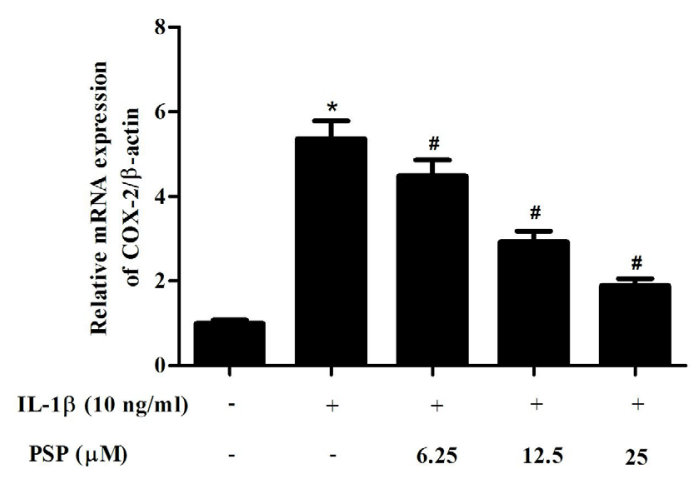

C

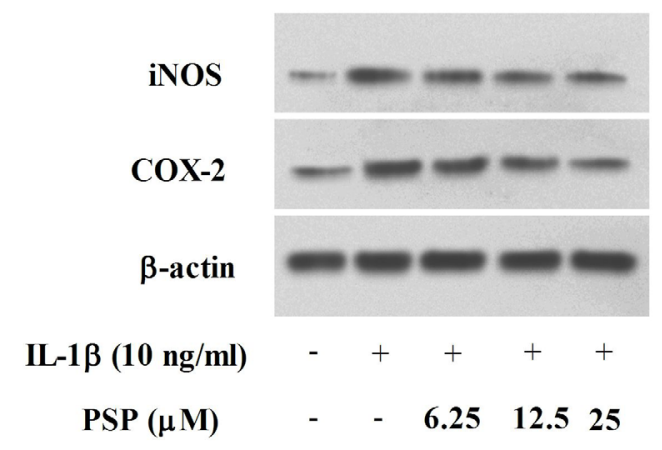

Figure 3. PSP suppressed the expressions of iNOS and COX-2 in IL- $1 \beta$-induced chondrocytes. Chondrocytes were pretreated with or without $6.25,12.5$ and $25 \mu \mathrm{M}$ PSP for $2 \mathrm{~h}$, and then treated with recombinant IL-1 $\beta(10 \mathrm{ng} / \mathrm{ml})$ for $24 \mathrm{~h}$; (A) and (B) The mRNA levels of iNOS and COX-2 were measured using qRT-PCR; (C) The protein levels of iNOS and COX-2 were detected using western blot; $\star$ indicated $p<0.05$ vs. control group; \# indicated $p<0.05$ vs. IL- $1 \beta$ stimulation group.

\subsection{PSP decreased production of MMP-1, MMP-3 and MMP-13 in IL-1ß-stimulated chondrocytes}

MMPs are important proteins involved in cartilage catabolism, the production of MMP-1, MMP-3 and MMP-13 were determined in chondrocytes. As shown in Figures $5 \mathrm{~A}-5 \mathrm{C}$, the increased production of MMP-1, MMP- 3 and MMP- 13 caused by IL- $1 \beta$ stimulation were dose-dependently decreased by PSP.

\subsection{PSP prevented IL-1 $\beta$-induced NF- $\kappa B$ activation in chondrocytes}

To further explore whether NF- $\mathrm{kB}$ signaling was involved in the effects of PSP, the expression levels of p-p65, p65, p-ІкBa and $\mathrm{IkBa}$ were detected using western blot. The results in Figure 6 showed that IL-1 $\beta$ treatment resulted in significant increase in the expressions of $\mathrm{p}-\mathrm{p} 65$ and $\mathrm{p}-\mathrm{I \kappa} \mathrm{B} \alpha$, indicating that IL- $1 \beta$ caused activation of NF- $\kappa B$ signaling. However, the PSP blocked IL-1 $\beta$-induced activation of NF- $\kappa B$ in chondrocytes.

\section{Discussion}

It is increasingly evident that inflammatory mechanisms play a central role in the development of OA (Abramson, 2004; Bonnet \& Walsh, 2005). A plethora of inflammatory mediators are unleashed and have the potential to be biomarkers of disease or therapeutic targets for prevention or treatment of OA (Abramson et al., 2001; Wang \& He, 2018). Elevated levels of TNF- $\alpha$, IL-1 $\beta$ and IL- 6 have been found in the synovial fluid, synovial membrane, subchondral bone and cartilage of OA patients, confirming their important roles in OA pathogenesis (Scanzello, 2017). In addition to the induction of other cytokines, the inflammatory mediators also stimulate the production of MMPs and prostaglandins, and inhibit the synthesis of proteoglycans and type II collagen, thereby regulating the cartilage matrix degradation and bone resorption in OA (Loeser, 2006; Wang \& He, 2018). IL-1 $\beta$ is usually used to stimulate inflammation in chondrocytes in vitro. Previous studies report that IL- $1 \beta$ induces the expressions of COX-2 and iNOS in chondrocytes, which may consequently lead to a higher production of inflammatory mediators, NO and PGE2 (Zheng et al., 2017; Zhuang et al., 2017). Our results proved that IL-1 $\beta$ stimulation caused decrease in cell viability, as well resulted in increase in the production of inflammatory mediators (NO, PGE2, COX-2 and iNOS) and the inflammation cytokines (TNF- $\alpha$ and IL-6) in chondrocytes.

PSP has many pharmacological applications and biological activities, including anti-inflammatory activity. Zhu et al., 2018 reported that PSP suppresses the production of TNF- $\alpha$, IL-6, malondialdehyde (MDA) and NO, and inhibit expression levels of myocardial Bax and cleaved Caspase- 3 protein in acute heart failure in rats. The results indicate that PSP exerts protective effects on acute heart failure, which is attributed to its anti-oxidative, anti-inflammatory activity and inhibition of cardiac myocyte apoptosis. PSP has been reported to promote osteoblast formation and blocks osteoclastogenesis through regulation of $\mathrm{Wnt} / \beta$-catenin signaling pathway (Du et al., 2016). Further investigations demonstrate that PSP regulates bone marrow-derived macrophages to osteoclast differentiation (Li et al., 2019). In addition, PSP prevents ovariectomy-induced bone loss in rats, as evidenced by increased bone mineral density (BMD), and lower levels of bone Gla protein (BGP), bone alkaline phosphatase (BALP), tartrate-resistant acid phosphatase (TRAP) and TNF- $\alpha$ (Zeng et al., 2011). The findings suggest that PSP may be used for the enhancement of bone health and prevention of osteoporosis. In the present study, we investigated the effects 
A
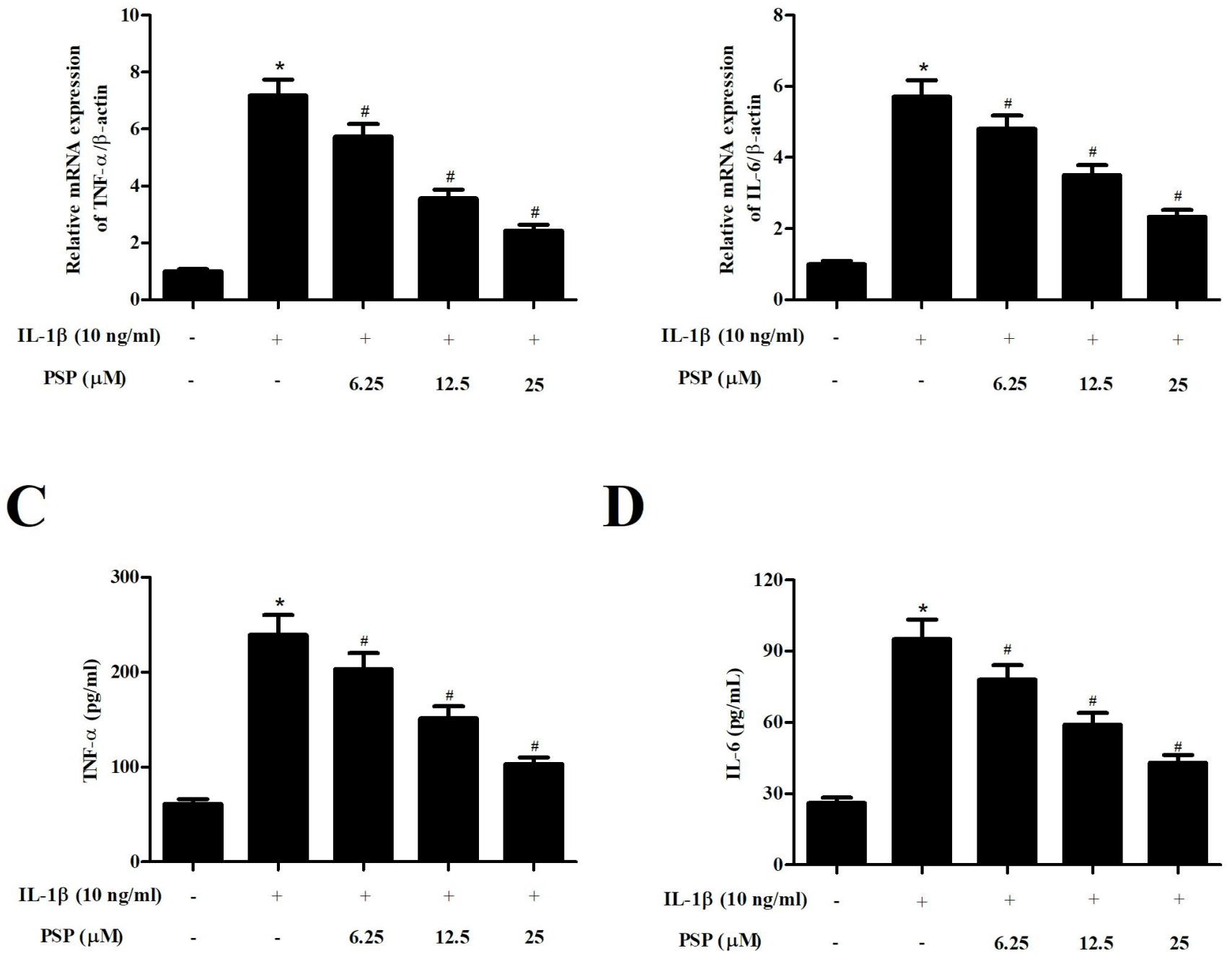

Figure 4. PSP suppressed the IL-1 $\beta$-stimulated production of TNF- $\alpha$ and IL- 6 in chondrocytes. Chondrocytes were pretreated with or without various concentrations of PSP $(6.25,12.5$ and $25 \mu \mathrm{M})$ for $2 \mathrm{~h}$, and then treated with recombinant IL-1 $\beta$ (10 ng/ml) for $24 \mathrm{~h}$; (A) and (B) The mRNA levels of TNF- $\alpha$ and IL-6 were measured using qRT-PCR; (C) and (D) The protein levels of TNF- $\alpha$ and IL- 6 were detected using western blot; ${ }^{\star}$ indicated $p<0.05$ vs. control group; \# indicated $p<0.05$ vs. IL- $1 \beta$ stimulation group.

of PSP on IL-1 $\beta$-induced inflammatory response in human OA chondrocytes. The results showed that PSP improved cell viability of IL- $1 \beta$-induced chondrocytes. The increased NO, PGE2, COX-2 and iNOS levels in IL-1 $\beta$-induced chondrocytes were attenuated by PSP. Besides, the IL- $1 \beta$-induced production of TNF- $\alpha$ and IL- 6 were mitigated by PSP in chondrocytes. These findings suggested that PSP prevented IL- $1 \beta$-induced inflammatory response in chondrocytes.

The NF- $\mathrm{KB}$ proteins are a family of ubiquitously expressed transcription factors that are involved in various cellular processes, such as oxidative stress, inflammatory responses, cell proliferation and cell death (Oeckinghaus \& Ghosh, 2009). The NF- $\kappa \mathrm{B}$ transcription factors are stimulated by pro-inflammatory cytokines, chemokines, stress-related factors and extracellular matrix (ECM) degradation products under pathological condition (Lawrence, 2009; Oeckinghaus \& Ghosh, 2009). During the development of $\mathrm{OA}$, the pro-inflammatory mediators lead to the induction of NF- $\mathrm{KB}$ signaling pathway, and subsequently promote the production of inflammatory cytokines, acting in a positive feedback loop to augment NF- $\mathrm{KB}$ activation (Rigoglou \& Papavassiliou, 2013; Saito \& Tanaka, 2017). NF-кB activation also contributes to the induction of NO, COX-2, NOS and PGE2, which promote synthesis of catabolic factors, cartilage inflammation and apoptosis of OA chondrocytes. In addition, the activation of NF- $\mathrm{kB}$ signaling pathway trigger the expression of many degradative enzymes, including MMP-1, MMP-2, MMP-3, MMP-7, MMP-8, MMP-9, MMP-13, ADAMTS-4 and 
A

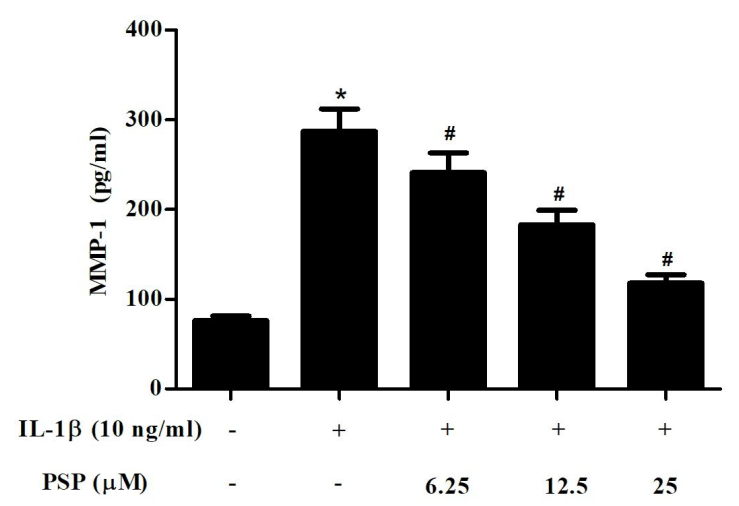

B

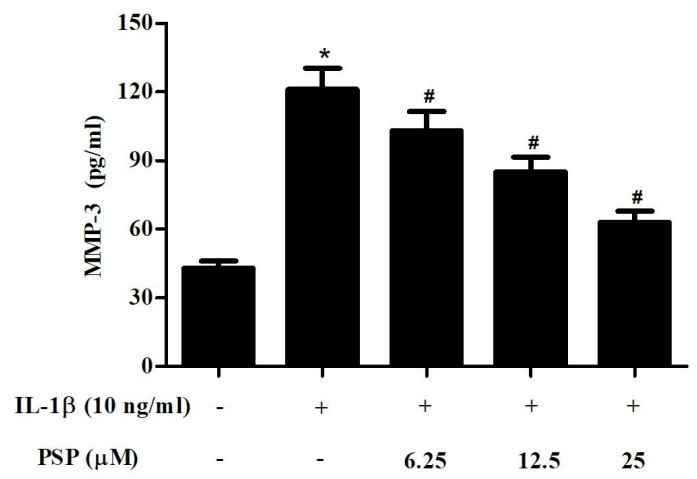

C

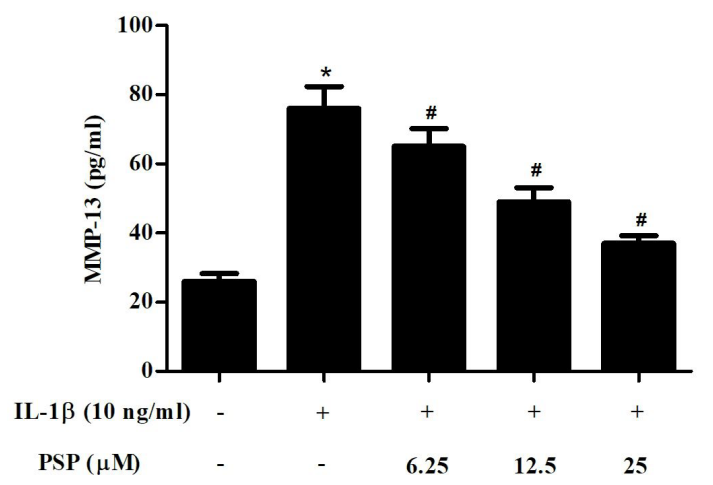

Figure 5. PSP decreased production of MMPs in IL-1 $\beta$-stimulated chondrocytes. Chondrocytes were pretreated with or without various concentrations of PSP $(6.25,12.5$ and $25 \mu \mathrm{M})$ for $2 \mathrm{~h}$, followed by stimulation with $10 \mathrm{ng} / \mathrm{ml}$ recombinant IL- $1 \beta$ for $24 \mathrm{~h}$; The production of MMPs including MMP-1 (A); MMP-3 (B); and MMP-13 (C) were determined using ELISA; ${ }^{*}$ indicated $p<0.05$ vs. control group; \# indicated $p<0.05$ vs. IL- $1 \beta$ stimulation group.

ADAMTS-5, leading to articular cartilage breakdown (Rigoglou \& Papavassiliou, 2013). Therefore, targeting NF- $\mathrm{BB}$ signaling cascade is a promising therapeutic strategy for OA treatment. Our results showed that PSP blocked IL-1 $\beta$-induced activation of NF- $\kappa B$ in chondrocytes, which might contribute to its inhibitory effect on IL- $1 \beta$-induced inflammation.
A

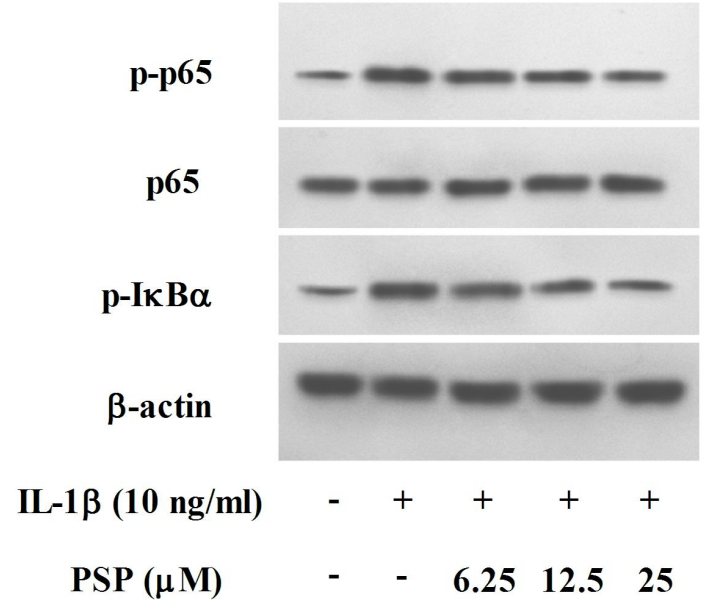

B
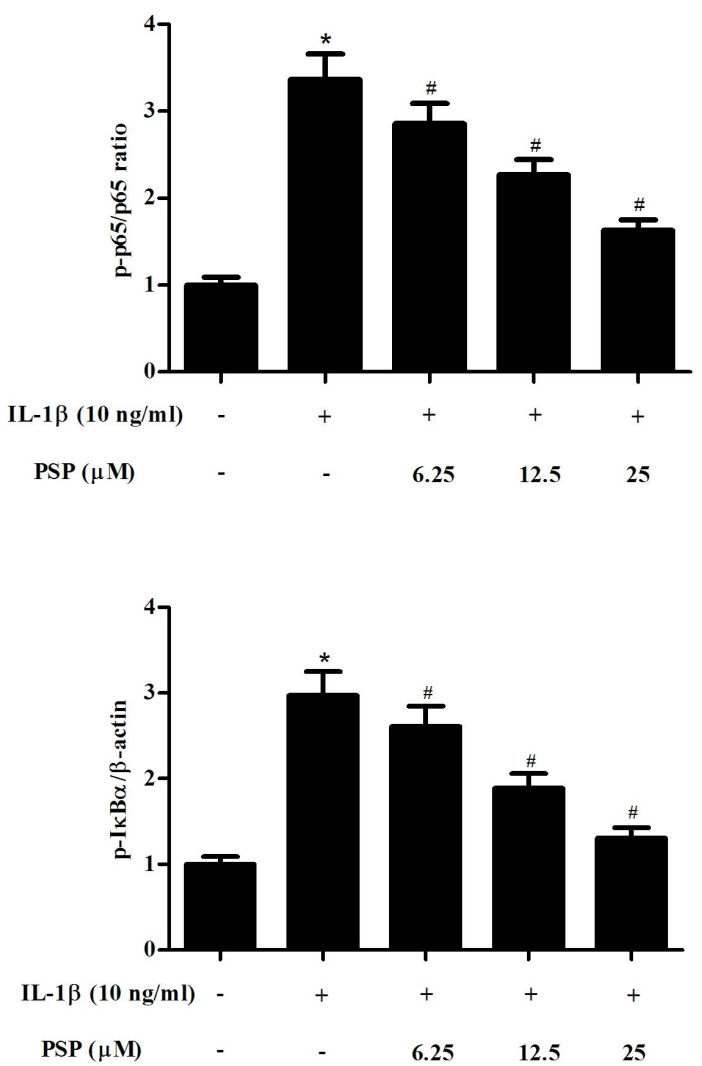

Figure 6. PSP prevented the activation of NF- $\kappa \mathrm{B}$ in IL- $1 \beta$-induced chondrocytes. Chondrocytes were treated with or without various concentrations of PSP $(6.25,12.5$ and $25 \mu \mathrm{M})$ for $2 \mathrm{~h}$, followed by stimulation with $10 \mathrm{ng} / \mathrm{ml}$ recombinant IL- $1 \beta$ for $1 \mathrm{~h}$; The expression levels of $\mathrm{p}-\mathrm{p} 65$, p65 and p-IkB $\alpha$ were detected using western blot $(\mathrm{A})$; and quantification analysis (B), (C); ${ }^{*}$ indicated $p<0.05$ vs. control group; \# indicated $p<0.05$ vs. IL- $1 \beta$ stimulation group.

In summary, our results demonstrated that PSP protected chondrocytes from IL- $1 \beta$-induced inflammation, which might be mediated by suppression of NF- $\kappa \mathrm{B}$ signaling pathway (Figure 7). Thus, PSP might serve as a potential anti-osteoarthritic agent. 


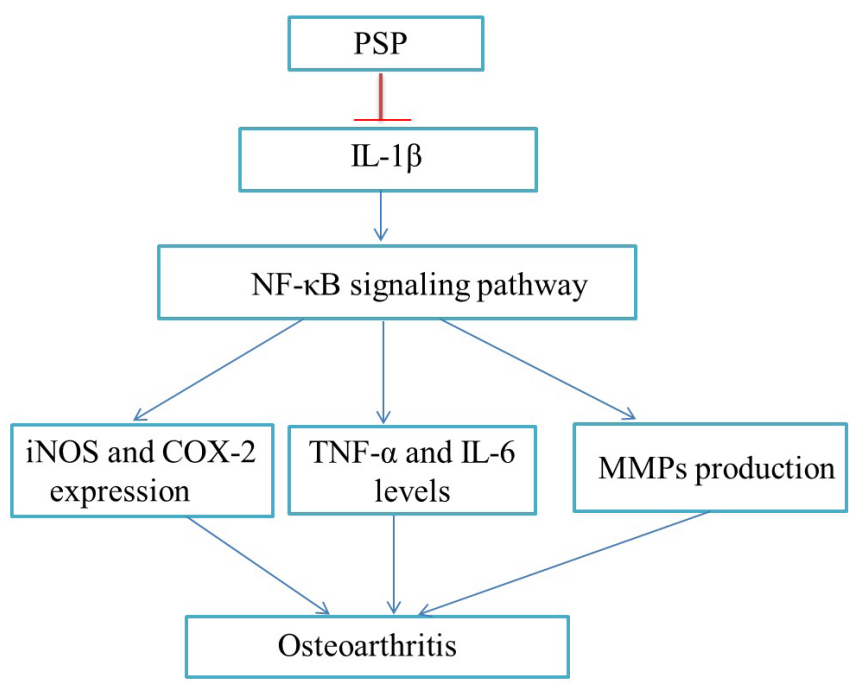

Figure 7. Schematic model of PSP-inhibited IL- $1 \beta$-induced inflammatory response in chondrocytes via inhibiting NF- $\kappa \mathrm{B}$ signaling pathway.

\section{References}

Abramson, S. B. (2004). Inflammation in osteoarthritis. The Journal of Rheumatology Supplement, 70(70), 70-76. PMid:15132359.

Abramson, S. B., Attur, M., Amin, A. R., \& Clancy, R. (2001). Nitric oxide and inflammatory mediators in the perpetuation of osteoarthritis. Current Rheumatology Reports, 3(6), 535-541. http://dx.doi. org/10.1007/s11926-001-0069-3. PMid:11709117.

Bonnet, C. S., \& Walsh, D. A. (2005). Osteoarthritis, angiogenesis and inflammation. Rheumatology, 44(1), 7-16. http://dx.doi.org/10.1093/ rheumatology/keh344. PMid:15292527.

Chen, J., Gu, Y. T., Xie, J. J., Wu, C. C., Xuan, J., Guo, W. J., Yan, Y. Z., Chen, L., Wu, Y. S., Zhang, X. L., Xiao, J., \& Wang, X. Y. (2018). Gastrodin reduces IL-1 $\beta$-induced apoptosis, inflammation, and matrix catabolism in osteoarthritis chondrocytes and attenuates rat cartilage degeneration in vivo. Biomedicine and Pharmacotherapy, 97, 642-651. http://dx.doi.org/10.1016/j.biopha.2017.10.067. PMid:29101808.

Cui, X., Wang, S., Cao, H., Guo, H., Li, Y., Xu, F., Zheng, M., Xi, X., \& Han, C. (2018). A review: the bioactivities and pharmacological applications of Polygonatum sibiricum polysaccharides. Molecules, 23(5), 1170. http://dx.doi.org/10.3390/molecules23051170. PMid:29757991.

Du, L., Nong, M. N., Zhao, J. M., Peng, X. M., Zong, S. H., \& Zeng, G. F. (2016). Polygonatum sibiricum polysaccharide inhibits osteoporosis by promoting osteoblast formation and blocking osteoclastogenesis through Wnt/beta-catenin signalling pathway. Scientific Reports, 6(1), 32261. http://dx.doi.org/10.1038/srep32261. PMid:27554324.

Felson, D. T. (2006). Osteoarthritis of the knee. The New England Journal of Medicine, 354(8), 841-848. http://dx.doi.org/10.1056/ NEJMcp051726. PMid:16495396.

Lawrence, T. (2009). The Nuclear Factor NF-кB Pathway in Inflammation. Cold Spring Harbor Perspectives in Biology, 1(6), a001651. http:// dx.doi.org/10.1101/cshperspect.a001651. PMid:20457564.

Li, B., Wu, P., Fu, W., Xiong, Y., Zhang, L., Gao, Y., Deng, G., Zong, S., \& Zeng, G. (2019). the role and mechanism of miRNA-1224 in the Polygonatum sibiricum polysaccharide regulation of bone marrowderived macrophages to osteoclast differentiation. Rejuvenation Research, 22(5), 420-430. http://dx.doi.org/10.1089/rej.2018.2126. PMid:30632458.

Loeser, R. F. (2006). Molecular mechanisms of cartilage destruction: mechanics, inflammatory mediators, and aging collide. Arthritis and Rheumatism, 54(5), 1357-1360. http://dx.doi.org/10.1002/ art.21813. PMid:16645963.

Loeser, R. F., Goldring, S. R., Scanzello, C. R., \& Goldring, M. B. (2012). Osteoarthritis: a disease of the joint as an organ. Arthritis and Rheumatism, 64(6), 1697-1707. http://dx.doi.org/10.1002/art.34453. PMid:22392533.

Malemud, C. J. (2015). Biologic basis of osteoarthritis. Current Opinion in Rheumatology, 27(3), 289-294. http://dx.doi.org/10.1097/ BOR.0000000000000162. PMid:25784380.

Marchev, A. S., Dimitrova, P. A., Burns, A. J., Kostov, R. V., DinkovaKostova, A. T., \& Georgiev, M. I. (2017). Oxidative stress and chronic inflammation in osteoarthritis: can NRF2 counteract these partners in crime? Annals of the New York Academy of Sciences, 1401(1), 114-135. http://dx.doi.org/10.1111/nyas.13407. PMid:28662306.

Oeckinghaus, A., \& Ghosh, S. (2009). The NF-kappaB family of transcription factors and its regulation. Cold Spring Harbor Perspectives in Biology, 1(4), a000034. http://dx.doi.org/10.1101/cshperspect. a000034. PMid:20066092.

Rahmati, M., Mobasheri, A., \& Mozafari, M. (2016). Inflammatory mediators in osteoarthritis: a critical review of the state-of-the-art, current prospects, and future challenges. Bone, 85, 81-90. http:// dx.doi.org/10.1016/j.bone.2016.01.019. PMid:26812612.

Rigoglou, S., \& Papavassiliou, A. G. (2013). The NF-kappaB signalling pathway in osteoarthritis. The International Journal of Biochemistry \& Cell Biology, 45(11), 2580-2584. http://dx.doi.org/10.1016/j. biocel.2013.08.018. PMid:24004831.

Saito, T., \& Tanaka, S. (2017). Molecular mechanisms underlying osteoarthritis development: notch and NF-kappaB. Arthritis Research \& Therapy, 19(1), 94. http://dx.doi.org/10.1186/s13075-017-1296-y. PMid:28506315.

Scanzello, C. R. (2017). Chemokines and inflammation in osteoarthritis: insights from patients and animal models. Journal of Orthopaedic Research, 35(4), 735-739. http://dx.doi.org/10.1002/jor.23471. PMid:27808445.

Shen, J., Abu-Amer, Y., O’Keefe, R. J., \& McAlinden, A. (2017). Inflammation and epigenetic regulation in osteoarthritis. Connective Tissue Research, 58(1), 49-63. http://dx.doi.org/10.1080/03008207 2016.1208655. PMid:27389927.

Wang, T., \& He, C. (2018). Pro-inflammatory cytokines: the link between obesity and osteoarthritis. Cytokine \& Growth Factor Reviews, 44, 3850. http://dx.doi.org/10.1016/j.cytogfr.2018.10.002. PMid:30340925.

Zeng, G. F., Zhang, Z. Y., Lu, L., Xiao, D. Q., Xiong, C. X., Zhao, Y. X., \& Zong, S. H. (2011). Protective effects of Polygonatum sibiricum polysaccharide on ovariectomy-induced bone loss in rats. Journal of Ethnopharmacology, 136(1), 224-229. http://dx.doi.org/10.1016/j. jep.2011.04.049. PMid:21550389.

Zhao, P., Zhao, C., Li, X., Gao, Q., Huang, L., Xiao, P., \& Gao, W. (2018). The genus Polygonatum: a review of ethnopharmacology, phytochemistry and pharmacology. Journal of Ethnopharmacology, 214, 274-291. http://dx.doi.org/10.1016/j.jep.2017.12.006. PMid:29246502.

Zheng, W., Tao, Z., Cai, L., Chen, C., Zhang, C., Wang, Q., Ying, X., Hu, W., \& Chen, H. (2017). Chrysin attenuates IL-1beta-Induced expression of inflammatory mediators by suppressing NF-kappaB in human osteoarthritis chondrocytes. Inflammation, 40(4), 11431154. http://dx.doi.org/10.1007/s10753-017-0558-9. PMid:28364187.

Zhu, X., Wu, W., Chen, X., Yang, F., Zhang, J., \& Hou, J. (2018). Protective effects of Polygonatum sibiricum polysaccharide on acute heart failure in rats 1. Acta Cirurgica Brasileira, 33(10), 868-878. http:// dx.doi.org/10.1590/s0102-865020180100000001. PMid:30484496.

Zhuang, Z., Ye, G., \& Huang, B. (2017). Kaempferol alleviates the interleukin-1 $\beta$-Induced inflammation in rat osteoarthritis chondrocytes via suppression of NF- $\kappa$ B. Medical Science Monitor, 23, 3925-3931. http://dx.doi.org/10.12659/MSM.902491. PMid:28806392. 